\title{
Analisis Kualitatif Faktor-Faktor Pendukung Kepatuhan Pasien Infeksi dalam Menggunakan Antibiotik Sefiksim Setelah Masa Rawat Inap di Rumah Sakit Prof. Dr. Margono Soekarjo
}

\section{Qualitative Analysis of Supporting Adherence Factors in Patient with Infection in Using of Cefixime Antibiotic Post Inpatient at Prof. Dr. Margono Soekarjo Hospital}

\author{
Elisa Mahardika, \\ Laksmi Maharani, Masita \\ Wulandari Suryoputri* \\ *Jurusan Farmasi \\ Fakultas Ilmu-Ilmu Kesehatan \\ Universitas Jenderal Soedirman \\ masitawulandarisuryoputri@gmail.com
}

Kata kunci: kepatuhan, sefiksim, indepth interview

Keywords: compliance, cefixime,
indepth interview

\section{ABSTRAK}

Penggunaan antibiotik harus sesuai dengan regimen yang telah ditentukan dokter atau apoteker untuk mencegah resistensi. Pasien setelah masa rawat inap berpotensi pada masalah kepatuhan dalam penggunaan antibiotik. Penelitian ini bertujuan untuk mengeksplorasi faktor-faktor pendukung kepatuhan pasien infeksi dalam menggunakan antibiotik sefiksim setelah masa rawat inap di Rumah Sakit Prof. Dr. Margono Soekarjo. Penelitian dilakukan menggunakan metode non-experimental berdasarkan pada pendekatan kualitatif fenomenologis dengan cara wawancara mendalam (indepth interview). Wawancara dilakukan dua kali pada hari ke-7 setelah keluar dari rumah sakit dan satu minggu setelah wawancara pertama. Hasil wawancara dianalisis secara deskriptif dengan proses berfikir induktif. Hasil penelitian menunjukkan bahwa faktor-faktor pendukung kepatuhan pasien infeksi dalam meminum antibiotik sefiksim setelah masa rawat inap adalah keinginan untuk sembuh, informasi bahwa antibiotik harus dihabiskan, takut terjadi kekambuhan, diingatkan anggota keluarga, bentuk sediaan, kondisi kesehatan yang memburuk dan mengikuti saran dokter. Selain itu, didapatkan hasil bahwa pasien patuh meminum dan menghabiskan antibiotik sesuai aturan pakai. Pasien mendapat mendapat manfaat dari etiket yang membantunya dalam mengingat jam minum obat. Antibiotics should be used in accordance with the regimen that has determined by doctors or pharmacists to prevent resistance. Ambulatory patients have the potential for compliance issues in antibiotic use. This research aims to explore the factors supporting adherence of patients in using cefixime antibiotic after the hospitalization at Prof. Dr. Margono Soekarjo Hospital. The research was conducted using in-depth interviews. The interview was conducted twice on the 7th day after discharge and one week after the first interview. Interview results were analyzed descriptively. The factors supporting adherence to consume cefixime after discharge was the willingness to recover, the right information to spent the antibiotic, fears of recurrence, reminding by the family, the acceptability dosage form, the deteriorating health condition, and following doctor suggestion. We found that all patients have high compliance in using antibiotics. They received a benefit from leaflets as a reminder to consume antibiotics. 


\section{Pendahuluan}

Antibiotik adalah golongan senyawa baik alami maupun sintetik yang mempunyai efek menekan atau menghentikan suatu proses biokimia di dalam organisme, khususnya dalam proses infeksi oleh bakteri (Kemenkes RI ${ }^{\mathrm{a}}$, 2011). Antibiotik yang banyak digunakan di Indonesia pada pasien rawat inap adalah golongan penisilin dan sefalosporin (Kemenkes, 2010). Frekuensi pemakaian antibiotik yang tinggi tetapi tidak diimbangi dengan ketentuan yang sesuai atau tidak rasional dapat menimbulkan dampak negatif salah satunya dapat terjadi resistensi (Erlangga, 2017). Apabila bakteri telah resistensi terhadap antibiotik maka morbiditas, mortalitas, dan biaya kesehatan akan meningkat (Kemenkes RI ${ }^{\mathrm{a}}$, 2011). Beberapa antibiotik yang mengalami resistensi misalnya ampisillin, amoksisillin dan sefotaksim. Angka resistensi golongan penisillin sebesar $73 \%$, sedangkan golongan sefalosporin hanya 13\% sehingga lebih banyak dipilih untuk pasien rawat inap karena angka resistensinya rendah (Kemenkes, 2010).

Antibiotik golongan sefalosporin generasi ketiga yang banyak digunakan untuk pasien rawat inap yaitu seftriakson sebesar 41-44 \% dan sefotaksim sebesar 11\% (Rachmawati, 2014; Yudha, 2013). Durasi terapi seftriakson dan sefotaksim yaitu 14-21 hari (Elizabeth et al, 2008), sedangkan berdasarkan uji pendahuluan di RSUD Prof. Dr. Margono Soekarjo lama rawat inap pasien infeksi dengan terapi seftriakson kurang dari 14 hari. Oleh karena itu, saat keluar rumah sakit pasien perlu diberikan antibiotik untuk memenuhi durasi terapi.

Berdasarkan studi pendahuluan di RSUD Prof. Dr. Margono Soekarjo, dari 20 pasien infeksi dengan terapi seftriakson yang telah selesai rawat inap, 15 pasien diberikan antibiotik sefiksim, sedangkan 5 pasien lainnya diberikan antibiotik golongan yang lain saat keluar rumah sakit. Pasien setelah masa rawat inap berpotensi pada masalah kepatuhan dalam terapi antibiotik. Oleh karena itu, diperlukan analisis secara kualitatif untuk mengetahui faktor-faktor pendukung kepatuhan pasien dalam menggunakan antibiotik agar terhindar dari ketidakpatuhan pasien sehingga meminimalkan angka resistensi.

Penelitian ini bertujuan untuk mengeksplorasi mengenai faktor-faktor pendukung kepatuhan pasien infeksi dalam menggunakan terapi antibiotik sefiksim setelah masa rawat inap di Rumah Sakit Prof. Dr. Margono Soekarjo.

\section{Metode Penelitian}

\section{Desain penelitian}

Penelitian yang dilakukan adalah penelitian non-experimental berdasarkan pada pendekatan kualitatif fenomenologis dengan cara wawancara mendalam (indepth interview).

\section{Lokasi dan waktu penelitian}

Pengambilan data dalam penelitian dilaksanakan selama 1 bulan dilakukan dengan wawancara dirumah responden yang berada di Kabupaten Banyumas, Jawa Tengah.

\section{Responden penelitian}

Responden penelitian adalah pasien infeksi yang patuh menggunakan terapi antibiotik sefiksim setelah periode rawat inap di Rumah Sakit Prof. Dr. Margono Soekarjo yang diketahui dengan tidak menyisakan lebih dari 2 kapsul. Kriteria lain yaitu bersedia mengisi dan menerima 
informed consent, berdomisili di Kabupaten Banyumas, berusia 18-60 tahun, dan dapat berkomunikasi dengan baik. Penentuan jumlah responden dianggap telah memadai apabila telah mencapai kejenuhan, artinya dengan menggunakan penambahan responden tidak lagi diperoleh tambahan informasi baru yang berarti (Moleong, 2007). Dalam penelitian ini untuk menentukan kejenuhan data dilakukan dengan mengadopsi literatur ilmiah lainnya.

\section{Alur penelitian}

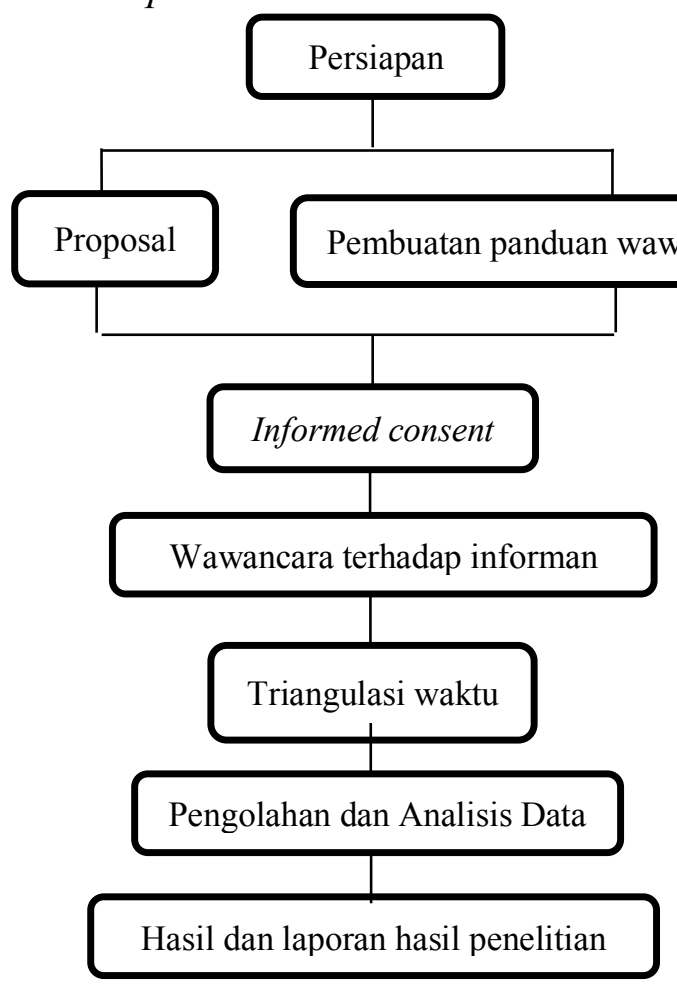

Gambar 1. Alur Penelitian

\section{Instrumen penelitian}

Instrumen yang digunakan dalam pengumpulan data adalah kuisioner, materi wawancara, dan alat perekam suara. Materi wawancara merupakan pedoman wawancara yang terdiri dari berbagai pertanyaan peneliti kepada responden sehingga dapat mengetahui faktor-faktor pendukung kepatuhan pasien infeksi dalam menggunakan terapi antibiotik sefiksim setelah masa rawat inap di Rumah Sakit Prof. Dr. Margono Soekarjo.

\section{Sumber data}

Sumber data yang dimanfaatkan untuk penelitian ini adalah data primer, yaitu data yang diperoleh dari hasil wawancara kepada responden.

\section{Analisis data}

Analisis data menggunakan proses berpikir induktif, yang dalam pengujiannya bertitik tolak dari data yang terkumpul kemudian disimpulkan. Langkah pertama melakukan reduksi data dengan memasukkan transkrip hasil wawancara kedalam bentuk tabulasi yang ditandai denga urutan line tertentu, kemudian memaknai line-line tersebut menjadi frasa yang menyimbolkan dan menonjolkan pesan. Pemaknaan ini disebut juga dengan istilah 'coding'. Hasil coding setiap informan diperkecil lagi menjadi suatu tema individu. Tema individu yang tidak berbeda jauh atau sama dari setiap informan dikelompokkan menjadi satu tema penelitian.

\section{Hasil dan Pembahasan}

\section{Karakteristik informan}

Tabel 1. Karakteristik Informan

\begin{tabular}{|c|c|c|c|c|c|}
\hline Nama & Umur & Pendidikan & Pekerjaan & $\begin{array}{c}\text { Tanggal dan lama } \\
\text { wawancara pertama }\end{array}$ & $\begin{array}{l}\text { Tangigal dan lama } \\
\text { wawancara kedua }\end{array}$ \\
\hline $\mathrm{A}$ & 34 & SMK & Ibu rumah tangga & $\begin{array}{l}\text { 3 April } \\
(27: 01)\end{array}$ & $\begin{array}{l}0 \text { April } \\
(15: 10)\end{array}$ \\
\hline B & 48 & SD & Ibu rumah tangga & $\begin{array}{l}\text { 4 April } \\
(20: 15)\end{array}$ & $\begin{array}{l}1 \text { April } \\
(14: 04)\end{array}$ \\
\hline $\mathrm{C}$ & 60 & S1 & Pensiun & $\begin{array}{l}10 \text { April } \\
(25: 02)\end{array}$ & $\begin{array}{l}7 \text { April } \\
(20: 23)\end{array}$ \\
\hline $\mathrm{D}$ & 43 & SMA & Wiraswasta & $\begin{array}{l}14 \text { April } \\
(26: 23)\end{array}$ & $\begin{array}{l}21 \text { April } \\
(17: 03)\end{array}$ \\
\hline $\mathrm{E}$ & 43 & S1 & PNS & $\begin{array}{l}19 \text { April } \\
(20: 22)\end{array}$ & $\begin{array}{l}6 \text { April } \\
(14: 34)\end{array}$ \\
\hline $\mathrm{F}$ & 45 & S1 & Wiraswasta & $\begin{array}{l}\text { 23 April } \\
(20: 09)\end{array}$ & $\begin{array}{l}0 \text { April } \\
(15: 18)\end{array}$ \\
\hline
\end{tabular}


Keenam informan adalah pasien infeksi yang patuh dalam meminum antibiotik sefiksim dengan latar belakang umur, pendidikan terakhir dan pekerjaan berbeda.

\section{Faktor-faktor yang memengaruhi kepatuhan menggunakan terapi antibiotik}

Pada penelitian menunjukkan bahwa faktor yang mempengaruhi kepatuhan pasien dalam menggunakan terapi antibiotik adalah keinginan untuk sembuh. Menurut Chaplin (2006) motivasi sembuh adalah perilaku yang didorong oleh kebutuhan (need) yang ada pada individu dan diarahkan pada sasaran (goals) dimana kembalinya seseorang pada suatu kondisi kenormalan setelah menderita suatu penyakit. Pasien menginginkan kesembuhan karena sakit adalah suatu keadaan yang tidak menyenangkan yang menimpa seseorang sehingga menimbulkan gangguan aktivitas sehari-hari baik jasmani, rohani, maupun sosial (Kumar et al., 2007). Adanya gangguan secara fisik, psikologi dan fungsi sosial akan berpengaruh terhadap kualitas hidup pasien (Megari, 2013). Pasien yang sakit juga akan menanggung biaya tidak langsung (indirect cost) berupa hilangnya produktivitas dan hilangnya pendapatan (Libby et al., 2012). Oleh karena itu, pasien ingin kembali bekerja untuk mengembalikan produktivitas dan pendapatan atau beraktivitas lainnya misalnya pergi ke luar kota. Keinginan pasien untuk sembuh menjadi faktor pendorong utama mengapa bersedia atau patuh meminum obat. Menurut Nurwidji and Tsalits (2013) keinginan untuk sembuh adalah faktor penting untuk menunjang keberhasilan pengobatan dan ada hubungan antara motivasi kesembuhan dengan kepatuhan pasien dalam penatalaksanaan pengobatan. Pasien yang memiliki keinginan untuk sembuh patuh dalam meminum antibiotik
(Muljabar, 2014).

Faktor lain yang membuat pasien patuh dalam menghabiskan antibiotik adalah informasi yang pernah didapatkan pasien dari tenaga kesehatan. Menurut Siregar (2006) memberikan Informasi dapat meningkatkan pengetahuan, mengubah perilaku, memberikan motivasi dan meningkatkan kepatuhan pasien. Manfaat dari pemberian informasi adalah meningkatkan kepatuhan pasien dalam penggunaan obat, sehingga angka kematian dan kerugian (baik biaya maupun hilangnya produktivitas) dapat ditekan (Schnipper et al., 2006). Pasien yang diberikan informasi obat secara lengkap angka kepatuhannya lebih besar yaitu 40 - $48 \%$ sedangkan yang tidak diberikan informasi obat angka kepatuhannya hanya $38 \%$ (Ariani and Aditya 2016, Muljabar 2014). Pada penelitian ini pasien mengatakan bahwa salah satu faktor yang mempengaruhi kepatuhannya adalah informasi. Pasien mendapatkan informasi bahwa antibiotik harus dihabiskan. Pasien menganggap antibiotik penting dan bermanfaat untuk mencegah bakteri sehingga harus dihabiskan. Menurut kemenkes $\mathrm{RI}^{\mathrm{a}}$ (2011) antibiotik harus di minum secara teratur sesuai cara penggunaannya. Jika pasien dalam menggunakan antibiotik tidak patuh pada regimen pengobatan dan aturan minum obat maka akan memicu terjadinya resistensi. Dampak jika bakteri telah resistensi terhadap antibiotik adalah meningkatnya morbiditas, mortalitas dan meningkatnya biaya kesehatan.

Alasan pasien patuh menggunakan terapi antibiotik adalah takut terjadi kekambuhan. Salah satu pasien pada penelitian adalah penderita tifoid. Pasien meminum antibiotik dengan teratur karena tidak ingin merasakan kekambuhan yaitu demam. Menurut Cita (2011) demam merupakan gejala klinis pada penderita tifus yang dapat muncul 
secara tiba-tiba terutama sore ataupun malam hari sehingga apabila keluhan demam muncul kembali maka penderita akan merasakan ketidaknyamanan yaitu terganggunya kualitas tidur.

Faktor lain yang berpengaruh terhadap kepatuhan adalah adanya dukungan keluarga, menurut Effendy (2006) seseorang yang sakit sangat membutuhkan dukungan dari orangorang terdekatnya, yaitu keluarga. Dukungan dapat ditujukan melalui sikap seperti mengingatkan penderita harus minum obat, menyiapkan obat yang harus diminum dan motivasi pada penderita untuk kesembuhan. Pada penelitian ini menunjukkan bahwa pasien mendapatkan dukungan dari keluarga yaitu diingatkan dalam meminum obat dan diambilkan obatnya, bahkan ada juga pasien yang mendapatkan motivasi dari anggota keluarganya untuk kesembuhan. Pasien mengatakan bahwa dengan adanya peran anggota keluarga seperti adik ataupun isteri pasien dalam mengingatkan minum obat membuat pasien patuh meminum antibiotik hingga habis. Hal tersebut sesuai dengan hasil penelitian dari Kartikasari et al. (2012), menyatakan bahwa PMO (pengawas minum obat) yang berasal dari anggota keluarga dianggap memiliki peran yang besar dalam meningkatkan kepatuhan pengobatan pasien, misalnya memotivasi pasien dan melakukan pengawasan secara langsung kepada pasien saat pengobatan, karena keluarga adalah orang yang paling dekat dengan pasien. Pasien yang mendapatkan PMO dari keluarga, yang patuh sebesar 80,6 \% dan yang tidak patuh hanya $19,4 \%$.

Alasan lain yang membuat pasien patuh meminum antibiotik adalah bentuk sediaan obat. Pada penelitian Wijayanti and Eni (2014) menyatakan bahwa bentuk sediaan antibiotik yang paling banyak diresepkan untuk pasien dewasa adalah tablet sebesar 90,50\%. Tablet merupakan salah satu sediaan farmasi yang sangat digemari, karena bentuknya yang padat, mudah di bawa dan dapat menghasilkan efek yang cepat, namum tablet memiliki kelemahan yaitu tidak dapat menutupi bau dan rasa (Agoes, 2012). Pasien dalam penelitian ini juga mengatakan bahwa sebelumnya pernah mendapatkan antibiotik dengan bentuk sediaan tablet dan merasakan tidak nyaman dikarenakan berbau, sedangkan antibiotik yang di dapatkan pasien setelah masa rawat inap di Rumah Sakit Prof. Dr. Margono Soekarjo adalah sefiksim kapsul. Sediaan kapsul memiliki kerugian dan keuntungan, menurut Syamsuni (2007) kerugian sediaan kapsul yaitu tidak bisa untuk dibagi-bagi, tidak bisa untuk zat-zat yang bereaksi dengan cangkang kapsul, tidak bisa untuk zat-zat yang higroskopis dan tidak bisa untuk balita, sedangkan keuntungan sediaan kapsul yaitu memiliki bentuk yang menarik dan praktis, cangkang kapsul tidak berasa sehingga dapat menutupi obat yang berasa dan berbau tidak enak serta mudah ditelan dan cepat hancur atau larut dalam perut sehingga obat cepat diabsorpsi. Keuntungan dari sediaan kapsul tersebut juga dirasakan pasien dalam penelitian ini, pasien mengatakan bahwa merasa nyaman meminum sefiksim dalam bentuk sediaan kapsul dikarenakan dapat menutupi bau serta ukuran kapsulnya kecil yang memudahkan pasien untuk menelan sehingga berpengaruh terhadap kepatuhan dalam meminum obat.

Pada penelitian terdapat satu pasien yang menyatakan bahwa merasakan kondisinya memburuk dan merasakan sakit yang paling parah dari sakit yang pernah dialami karena pasien juga mengalami gagal ginjal. Keadaan pasien yang memburuk membuatnya menjalani rawat inap. Pelayanan rawat inap merupakan kebutuhan yang mendasar 
bagi pasien dalam rangka upaya penyembuhan penyakitnya. Tujuan utama pasien untuk berobat adalah adanya keinginan untuk sembuh dari penyakit yang diderita yang akhirnya mendorong pasien untuk memenuhi kebutuhannya dengan cara memanfaatkan rawat inap (Andayanie et al., 2010). Menurut Azam and Arulita (2011) kriteria pasien yang masuk rawat inap berdasarkan Appropriateness Evaluation Protocol (AEP) adalah pasien yang memiliki penyakit akut dan memberat meliputi gangguan kesadaran, hemodinamika, penginderaan, demam tinggi, kardiovaskuler dan cedera. Pasien dipenelitian ini merasa kondisinya memburuk ditandai dengan dirawat di rumah sakit yang membuatnya patuh dalam meminum obat. Sesuai dengan hasil penelitian Paterno et al. (2009) yang menyatakan bahwa tingkat keparahan pasien berpengaruh terhadap kepatuhan pasien yang lebih tinggi.

Pada hasil penelitian juga menunjukkan bahwa pasien patuh meminum antibiotik dikarenakan mengikuti anjuran atau saran dari dokter. Menurut Zanichelli et al. (2018) adanya instruksi dari dokter mengenai indikasi pengobatan antibiotik secara tertulis ataupun verbal berpengaruh terhadap kepatuhan pasien. Pasien dalam penelitian ini mengikuti anjuran atau saran dari dokter sehingga menunjukkan bahwa pasien memiliki rasa percaya terhadap dokter. Kepercayaan pasien terhadap dokter juga dibuktikan dengan adanya penelitian Alimin (2013) yang menyatakan bahwa dari 150 orang responden, semuanya mempercayai dokter saat konsultasi.

\section{Informasi obat}

Semua pasien yang diwawancarai pada penelitian ini patuh dalam meminum antibiotik dan menghabiskan antibiotik sesuai dengan aturan pakai. Pasien mendapatkan informasi aturan pakai obat dari etiket. Menurut Syamsuni (2007) pada etiket harus tercantum nama dan alamat apotek, nama dan nomor SIK Apoteker pengelola apotek, nomor dan tanggal pembuatan, nama pasien, aturan pemakaian, dan tanda lain yang diperlukan misalnya: kocok dahulu. Saat ini etiket sudah berkembang yaitu tercantum informasi jam penggunaan obat, manfaat atau kegunaan obat serta nama obat. Pemberian etiket pada kemasan obat merupakan salah satu metode tertulis yang digunakan untuk mempermudah pasien mengetahui informasi obat (Kurniawan and Chabib, 2010).

Pasien dalam penelitian ini mengatakan merasa terbantu dengan adanya etiket obat yang membuatnya mengetahui aturan pakai obat, bahkan beberapa pasien ada yang mengatakan bahwa aturan pakai di etiket menjadi pengingat jam minum obat dikarenakan pasien mendapatkan beberapa macam obat yang aturan pakainya berbeda-beda. Pasien patuh dalam meminum antibiotik hingga habis sesuai dengan aturan pakai yang ada di etiket yaitu diminum dua kali sehari, jam 7 pagi dan jam 7 malam. Ada satu pasien yang meminum antibiotik tidak sesuai dengan jam yang tertera tapi tepat dalam rentang 12 jam yaitu jam 8 pagi dan jam 8 malam. Jadi dapat dikatakan bahwa pasien memahami ketepatan interval waktu meminum obat karena obat yang harus diminum 2 kali sehari diartikan bahwa obat tersebut diminum dengan interval 12 jam (Kemenkes $\quad \mathrm{RI}^{\mathrm{b}}$, 2011). Antibiotik sefiksim merupakan antibiotik timedependent yang artinya kerja antibiotik akan maksimal apabila interval pemberian antibiotik tepat (Leekha et al, 2011). Ketepatan interval waktu minum obat harus dipatuhi dikarenakan disesuaikan dengan waktu paruh obat. Lama kerja obat tergantung dari waktu paruhnya, jadi waktu paruh merupakan 
pedoman penting untuk menentukan interval dosis obat. Obat yang memiliki waktu paruh pendek diberikan beberapa kali sehari dan obat dengan waktu paruh panjang (lebih dari 24 jam) diberikan sekali sehari (Lestari, 2016).

Selain dari etiket, pasien mengatakan sebelumnya pernah mendapatkan informasi mengenai penggunaan antibiotik yang harus dihabiskan dari tenaga kesehatan. Pemberian informasi tentang obat yang telah diterima (oral communication/counseling) dapat meningkatkan hasil terapi (Rantucci, 2007). Pemberian informasi pada pasien mengenai pemakaian antibiotik yang rasional akan berdampak baik untuk pengendalian penggunaan antibiotik di Indonesia dikarenakan pemahaman masyarakat tentang manfaat, penggunaan, serta dampak dari penggunaan antibiotik masih lemah (Kemenkes RI ${ }^{\mathrm{b}}$, 2016). Informasi umum mengenai penggunaan antibiotik terbesar diperoleh dari tenaga kesehatan dan berpengaruh terhadap kepatuhan meminum obat (Latifiana, 2006). Pada penelitian Sari (2014) disebutkan bahwa sebanyak $92 \%$ pasien mendapatkan informasi obat dari tenaga kesehatan meliputi dokter dan apoteker. Hasil tersebut selaras dengan hasil penelitian ini yaitu pasien sebagian besar mendapatkan informasi dari dokter dikarenakan dokter adalah tenaga kesehatan yang pertama kali bertemu dengan pasien pada saat pemeriksaan. Menurut Akici et al. (2004) informasi yang diberikan oleh dokter maupun apoteker sangat diperlukan untuk meningkatkan kepatuhan pasien karena informasi yang tidak sesuai memberikan pengetahuan yang kurang kepada pasien sehingga dapat menimbulkan ketidakpatuhan pasien dalam terapi pengobatan. Selain dari dokter, pasien dalam penelitian ini juga mendapatkan informasi dari apoteker pada saat menebus obat dan mengatakan bahwa apoteker lebih berkompeten dalam memberikan informasi. Peran apoteker adalah melakukan dispensing yang terdiri dari penyiapan, penyerahan dan pemberian informasi obat meliputi cara penggunaan dan hal-hal yang terkait dengan obat. Kegiatan pelayanan informasi obat yang dilakukan apoteker diantaranya menjawab pertanyaan lisan maupun tulisan dan memberikan edukasi kepada pasien (Kemenkes $\mathrm{RI}^{\mathrm{a}}$ and Kemenkes RIc ${ }^{c}$ 2016). Menurut penelitian Tjahyadi (2013) kinerja apoteker dalam melakukan pelayanan informasi obat sebesar $75 \%$ dan terdapat kepuasan dan kebermanfaatan informasi obat yang dirasakan oleh pengguna layanan informasi obat. Sebanyak 89,65 $\%$ pasien merasa puas terhadap pelayanan apoteker dalam aspek penyerahan obat, pemberian informasi obat maupun konseling (Wibowo et al., 2016).

Dalam mewujudkan dan mengubah persepsi pasien mengenai kepatuhan penggunaan antibiotik penting untuk dihabiskan agar tidak terjadi resistensi maka peran apoteker dalam memberikan informasi, edukasi atau konsultasi seputar penggunaan terapi antibiotik harus ditingkatkan. Dengan adanya kepatuhan dalam diri pasien mengenai penggunaan antibiotik yang rasional dan konsekuensi akibat resistensi yang bisa terjadi, maka terapi pun dapat berhasil (Bisht, 2009).

Dalam penelitian ini responden melakukan pencarian informasi obat secara mendiri di internet dengan tujuan mencarai manfaat obat. Hal tersebut menunjukkan bahwa informasi yang didapatkan dari apoteker masih belum memadai atau memuaskan bagi pasien sehingga saran bagi apoteker adalah memberikan waktu lebih untuk konseling, informasi dan edukasi ke 
pasien sebelum pasien keluar dari rumah sakit melalui visitasi ke pasien agar penjelasan terkait penggunaan obat, khususnya antibiotik dapat tersampaikan dengan baik sesuai dengan Standar Pelayanan Kefarmasian di Rumah Sakit.

\section{Simpulan}

Berdasarkan hasil penelitian yang telah dilakukan maka diperoleh kesimpulan yaitu faktor-faktor pendukung kepatuhan pasien infeksi dalam menggunakan antibiotik sefiksim setelah masa rawat inap di Rumah Sakit Prof. Dr. Margono Soekarjo yang didapat dari hasil wawancara peneliti kepada responden menggunakan materi wawancara adalah keinginan untuk sembuh, informasi bahwa antibiotik harus dihabiskan, takut terjadi kekambuhan, diingatkan anggota keluarga, bentuk sediaan, kondisi kesehatan yang memburuk dan mengikuti saran dokter. Selain itu, didapatkan hasil bahwa pasien patuh menggunakan terapi antibiotik serta menghabiskan sesuai aturan pakai, etiket membantu pasien dalam mengingat jam minum obat, pasien mendapatkan informasi antibiotik harus dihabiskan dari tenaga kesehatan dan pasien mendapatkan informasi manfaat obat dari internet.

\section{Daftar Pustaka}

Abdullah, A., 2011, Ilmu Alamiah Dasar, PT Bumi Aksara, Jakarta, 2.

Agoes, G., 2012, Sediaan Farmasi Padat (SFI-6), Penerbit ITB, Bandung, 16-17.

Akici, A., Sibel, K., Ugurlu, M.U., Toklu, H.Z., Iskender, E., and Sule, O., 2004, Patient Knowledge About Drugs Prescribed at Primary Healthcare Facilities, Pharmacoepidemiology and Drug Safety, 13:871-876.
Alimin, M., 2013, Hubungan Komunikasi (Mendengarkan, Menjelaskan Dan Kompetensi) Dengan Kepercayaan, Kepuasan Dan Loyalitas Pasien Instalasi Rawat, Skripsi, Unpublished, Fakultas Kesehatan Masyarakat Universitas Hasanuddin, Makassar.

Andayanie, E., Asiah, H., and Indar, 2010, Analisis Hubungan Antara Karakteristik Pasien Dengan Keputusan Untuk Memanfaatkan Rawat Inap Di Rsu Haji Kota Makassar, Jurnal MKMI, 6 (2):76-80.

Anief, M., 2010. Ilmu Meracik Obat. Gadjah Mada University Press, Yogyakarta, 23.

Ariani, N., and Aditya, M., 2016, Hubungan Pemberian Informasi Obat Dengan Kepatuhan Minum Obat Antibiotik Pada Pasien Rawat Jalan Di Puskesmas Remaja Samarinda, Prosiding Rakernas IAI, Akademi Farmasi ISFI, Banjarmasin, 148.

Azam, M., and Arulita, I.F., 2011, Sistem Informasi Admisi Pasien Membantu Ketepatan Pengambilan Keputusan Admisi Pasien, Jurnal Kesehatan Masyarakat, 6 (2):51-57.

Bisht, R., 2009, Antibiotic resistence - a global issue of concern, Asian Journal Pharmaceutical and Clinical Research, 2 (2):122-129.

Bosch, B., and Holly, M., 2015, Interprofessional collaboration in health care: Lessons to be learned from competitive sports, $C P J$, 148 (4):176-179.

Chaplin, J.P., 2006, Kamus Lengkap Psikologi, PT Raja Grafindo Persada, Jakarta, 23.

Cita, Y.P., 2011, Bakteri Salmonella Typhi dan Demam Tifoid, Jurnal Kesehatan Masyarakat, 6 (1):4245. 
Dipiro, J.T., Wells, G.B., Schwinghammer, L.T. and Dipiro, 2008, Pharmacotherapy Handbook Seven Edition, The McGraw-Hill Companies, United States of America, 1748.

Effendy, O.U., 2006, Ilmu Komunikasi; Teori dan Praktek, Remaja Rosda Karya, Bandung, 51-53.

Erlangga, D., 2017, Pola Peresepan Antibiotik Pada Pasein Rawat Jalan Di Puskesmans Dalam Wilayah Kota Pariaman, Skripsi, Unpublished, Fakultas Farmasi Universitas Andalas, Padang.

Fawkes, C., Elena, W., and Dawn, C., 2015, What evidence is good evidence? A masterclass in critical appraisal, International Journal of Osteopathic Medicine, 30:1-13.

Kartikasari, D., Sri, R., and Edy, W., 2012, Hubungan Peran Keluarga Sebagai Pengawas Minum Obat(Pmo) Dengan Kepatuhan Minum Obat Pada Penderita TB Paru Di Puskesmas Kedungwuni II Kabupaten Pekalongan, Jurnal Keperawatan, 5 (1):71-79.

Kemenkes RI, 2010, Antimicrobial Resistance, Antibiotic Usage and Infection Control, A SelfAssessment Program For Indonesian Hospital, Kementerian Kesehatan RI, Jakarta, 167.

Kemenkes RI ${ }^{\mathrm{a}}, \quad 2011$, Pedoman Pelayanan Kefarmasian Untuk Terapi Antibiotik, Kementerian Kesehatan RI, Jakarta, 5-13.

Kemenkes RI ${ }^{\mathrm{b}}, 2011$, Modul Penggunaan Obat Rasional, Kementerian Kesehatan RI, Jakarta, 5.

Kemenkes RI, 2014, Undang-undang Nomor 38 Tentang Keperawatan, Kementerian Kesehatan RI, Jakarta.
Kemenkes RI ${ }^{\mathrm{a}}$, 2016, Permenkes Nomor 73 Tentang Standar Pelayanan Kefarmasian di Apotek, Kementerian Kesehatan RI, Jakarta.

Kemenkes $\mathrm{RI}^{\mathrm{b}}$, 2016, Kemenkes dan Kementan Berkomitmen Untuk Kendalikan Resistensi Antimikroba, http://www.depkes.go.id, diakses 28 Juni 2018.

Kemenkes RI ${ }^{\mathrm{c}}$, 2016, Permenkes Nomor 72 Tentang Standar Pelayanan Kefarmasian di Rumah Sakit, Kementerian Kesehatan RI, Jakarta.

Kemenkes RI, 2017, Permenkes Nomor 28 Tentang Izin dan Penyelenggaraan Praktik Bidan, Kementerian Kesehatan RI, Jakarta.

Kumar,V., Abbas, A.K., Fausto, N., and Perkins, J. A., 2007, Basic Pathology $8^{\text {th }}$ Edition, Elsevier Inc, Philadelphia, 204-205.

Kurniawan, D.W., and Chabib, L., 2010, Pelayanan Informasi Obat Teori dan Praktik, Graha Ilmu, Yogyakarta, 30.

Latifiana, U., 2006, Faktor-faktor yang Berpengaruh Terhadap Kepatuhan Pasien Terhadap Penggunaan Antibiotika Oral Sesuai Resep Dokter, Skripsi, Fakultas Farmasi Universitas Airlangga, Surabaya.

Leekha, S., Terrell, C. L. and Edson, R. S., 2011, General Principles of Antimicrobial Therapy, Mayo Clin Proc, 86 (2):156-167.

Lestari, S., 2016, Farmakologi Dalam Keperawatan, Pusdik SDM Kesehatan, Jakarta, 6.

Libby, A.M., Ghushchyan, V., Robert, B.M., Julia, F.S., Jacqueline, L.B., and Jonathan, D.C., 2012, Economic Differences in Direct and Indirect Costs Between People With Epilepsy and 
Without Epilepsy, Med care, 50 (11):928-933.

Masic, I., Milan, M., and Belma, M., 2008, Evidence based medicine new approaches and challenges, Professional Paper, 16:219-225.

Megari, K., 2013, Quality of life in chronic disease patients, Health Psychology Research, 1 (27): 141-148.

Moleong, L.J., 2007, Metode Penelitian Kualitatif, PT Remaja Rosdakarya, Bandung, 142-165.

Muljabar, S., 2014, Pengaruh Pemberian Informasi Obat Terhadap Tingkat Kepatuhan Penggunaan Antibiotika Pada Pasien ISPA Di Puskesmas Kotagede I Yogyakarta, Pharmaciana, 4 (2):143-149.

Nurwidji and Tsalits, F., 2013, Hubungan Motivasi Kesembuhan Dengan Kepatuhan Penatalaksanaan Pengobatan Pada Pasien Tb Paru di Wilayah Kerja Puskesmas Mojosari Mojokerto, Medica Majapahit, 5 (2):68-82.

Paterno, M.D., Saverio, M.M., Paul, N.G., Diane, L.S., Eileen, Y., Andrew, C.S., David., W.B., et al., 2009, Tiering Drug-Drug Interaction Alerts By Severity Increases Compliance Rates, Original Investigations, 16:4046.

Rachmawati, Y., 2014, Evaluasi Penggunaan Antibiotik Pada Pasien Gastroenteritis Di Instalasi Rawat Inap Rumah Sakit "X" Periode Januari - Juni 2013, Skripsi, Unpublished, Fakultas Farmasi Universitas Muhammadiyah, Surakarta.

Rantucci, M.J., 2007, Komunikasi Apoteker-Pasien: Panduan Konseling Pasien, EGC, Jakarta, 15.

Sari, M., 2014, Studi Perbandingan Kepatuhan Penggunaan
Antibiotik Di Apotek Bhumyamca II dan Tiara 2, Skripsi, Unpublished, Fakultas Farmasi Unika Widya Mandala, Surabaya.

Schnipper, J.L., Kirwin, J.L., Cotugno, M.C., Wahlstrom, S.A., Brown, B.A., Tarvin, E., Kachalia, A., et al, 2006, Role of Pharmacist Counseling in Preventing Adverse Drug Events After Hospitalization, Archives of Internal Medicine, 166:565-571.

Shuangmei, T.M.B., Jiaqian, P.B., Shan, L.M.B., and Jing, T., 2018, Patient compliance with antimicrobial drugs: A Chinese survey, American Journal of Infection Control, 46:25-29.

Siregar, 2006, Sikap Kepatuhan Dalam Tindakan, Mitra Media, Jakarta, 22-23.

Suherman, 2012, Media Pembelajaran Berbasis Komputer, Rineka Cipta, Jakarta, 21.

Syamsuni, 2007, Ilmu Resep, EGC, Jakarta, 21-56.

Tjahyadi, Y.E., 2013, Studi Pelaksanaan Pelayanan Informasi Obat di Rumah Sakit X Surabaya, Jurnal Ilmiah Mahasiswa Universitas Surabaya, 2 (1):1-22.

Waszak, P.M., Wioleta, K.W., and Alicja, K., 2018, The spread of medical fake news in social media - the pilot quantitative study, Health Policy and Technology, 3 (2):1-17.

Wibowo, M.I.N.A., Anjar, M.K., Umu, K., Rani, I.A.D., and Rahmawati, K.D., 2016, Tingkat Kepuasan Pasien Terhadap Kinerja Apoteker Puskesmas Di Tiga Kabupaten: Purbalingga, Banjarnegara dan Cilacap Tahun 2015, Pharmacy, 13 (1):46-70.

Wijayanti, A., and Eni, W., 2014, Evaluasi Peresepan Antibiotik Pada Pasien Dewasa Di 
Puskesmas Banguntapan 1 Bantul Yogyakarta, CERATA Journal of Pharmacy Science, 1:19-33.

Yudha, 2013, Evaluasi Penggunaan Antibiotik Pada Pasien Pneumonia Dengan Metode Gyssens Di Instalasi Rawat Inap Rumah Sakit Umum Dokter Moewardi Surakarta Tahun 2013, Skripsi, Fakultas Farmasi Universitas Muhammadiyah, Surakarta.

Zanichelli, V.G., Gyseeens, I.C., Palcevski, V.V., Monnier, A.A., Benic, M.S., Harbarth, S., Hulscher, M., et al, 2018, Patientrelated determinants of antibiotic use: a systematic review, Clinical Microbiology and Infection, $\mathbf{4}$ (31):1-20. 